\title{
Determinação do Potencial Fitorremediador da Eichhornia Crassipes em Ambientes Naturais
}

\author{
Myrelle Yasmine de Freitas Câmara* (Graduanda em Ciência e Tecnologia na Universidade Federal
}

Rural do Semi-árido - UFERSA);

Layane Érica da Silva Pinto (Graduanda em Ciência e Tecnologia na Universidade Federal Rural do

$$
\text { Semi-árido - UFERSA); }
$$

Fernanda Beatriz Aires de Freitas (Graduanda em Ciência e Tecnologia na Universidade Federal Rural do Semi-árido - UFERSA);

Francisco Gustavo Hayala Silveira Pinto (Graduando em Química na Universidade do Estado do Rio

$$
\text { Grande do Norte - UERN); }
$$

Anne Gabriella Dias Santos (Docente do curso de Química na Universidade do Estado do Rio Grande do Norte - UERN);

Daniel Freitas Freire Martins (Docente do curso de Ciência e Tecnologia na Universidade Federal Rural do Semi-árido - UFERSA).

*E-mail: myrelleyasmine@hotmail.com

\section{Resumo:}

Em meio às diversas atividades desenvolvidas pelo homem, algumas delas possuem a capacidade de liberar contaminantes que são perigosos à saúde humana e a outras formas de vida, como animais e vegetais, causando a degradação do meio ambiente. Por esse motivo, aumenta o interesse por técnicas remediadoras a fim de recuperar total ou parcialmente os ambientes impactados em especial, pela ação humana. Dentre elas, a fitorremediação possui um destaque devido à sua eficiência na descontaminação de ambientes eutrofizados e também devido ao seu baixo custo em relação aos demais. Portanto, o presente trabalho tem como objetivo determinar o potencial fitorremediador de macrófitas aquáticas da espécie Eichhornia crassipes presentes no rio Apodi/Mossoró em relação aos teores de alguns elementos utilizando a técnica de Fluorescência de Raios-X. A coleta da água e das plantas utilizadas foi feita no trecho do Rio Apodi/Mossoró que corta a cidade de Mossoró. A partir dos resultados obtidos, foram identificados na água do rio teores de $\mathrm{Br}, \mathrm{Ca}, \mathrm{Fe}, \mathrm{K}, \mathrm{Mn}, \mathrm{Rb}, \mathrm{S}$, Si e $\mathrm{Sr}$, e quanto a planta percebeu-se que os elementos $\mathrm{Br}$, Fe, Mn, S, Si, Ti, Zn, Al, V, Y, Zr, As, Cr, Eu, Ni, Pd, apresentaram-se em maiores concentrações nas raízes do que nas folhas. Já os elementos $\mathrm{Ca}, \mathrm{K}, \mathrm{Rb}, \mathrm{Sr}, \mathrm{Cl}, \mathrm{P}, \mathrm{Cu}$, apresentaram-se comportamento inverso, ou seja, maiores nas folhas. Sendo assim, essa espécie apresenta um grande potencial para ser utilizada em estratégias de fitorremediação de ambientes naturais, em função das quantidades acumuladas em seu tecido.

\section{Palavras-chave:}

Fitorremediação; Eichhornia crassipes, Rio Apodi/Mossoró; Ambientes contaminados; Ação antropogênica. 


\section{I NTRODUÇÃO}

Com o aumento desenfreado das indústrias desde a década de 90, o meio ambiente vem sofrendo degradações constantes e por isso vem merecendo um maior destaque no que diz respeito aos lançamentos de efluentes sobre os recursos hídricos e solos urbanos, uma vez que causa diversos problemas ao ambiente. No meio de atividades potencialmente poluidoras podem-se destacar as indústrias e as agrícolas, que com a pouca fiscalização, infelizmente, ainda descartam seus resíduos de forma incorreta, podendo vir a comprometer a saúde humana e a qualidade de todo o ecossistema.

Dentre os poluentes, os metais pesados representam o maior contaminante industrial de solos, corpos d'água, plantas e animais no ecossistema (GHOSHROY et al., 1998). Esses elementos, por sua vez, são considerados bioacumulativos. Assim, a contaminação dos recursos hídricos enfraquece consideravelmente a quantidade de água disponível para a utilização humana, tornando-se um problema grave devido esses metais não serem biodegradáveis (ARAÚJO e PINTO FILHO, 2010).

Com isso faz-se necessário utilizar de técnicas para descontaminação destes ambientes, as quais precisam aliar eficiência, simplicidade nas manutenções, menor tempo demandado e um baixo custo. Assim, surge o interesse pela biorremediação, caracterizada como uma técnica que tem por objetivo descontaminar o solo e a água por meio da utilização de organismos vivos, como microrganismos e plantas (PIRES et al., 2003).

Dentro da biorremediação, a fitorremediação é uma das técnicas mais estudadas. Segundo Tavares (2009) a fitorremediação se refere ao uso de plantas na descontaminação de ambientes poluídos, principalmente com metais pesados e poluentes orgânicos, reduzindo os teores desses elementos a níveis seguros à saúde humana, além de contribuir também na melhoria das características físicas, químicas e biológicas destas áreas. Uma de suas maiores potencialidades é o baixo custo, embora o tempo em que leva para que se observem os resultados seja considerada uma desvantagem, dependendo das perspectivas envolvidas na remediação.

Uma das plantas que apresenta esse potencial de limpeza são as macrófitas aquáticas. Define-se macrófitas como plantas herbáceas ou macroalgas que crescem na água, em solos saturados, ou em solos abrigados por água (SILVA, 2011). Originalmente, eram vegetais terrestres que, para se propagar em ambientes aquáticos, passaram por modificações adaptativas, sendo classificadas como submersas, emergentes, com folhas flutuantes e flutuantes livres (BIANCHINI JR, PACOBAHYBA, CUNHASANTINO, 2002; CAMARGO, PEZZATO, HENRY-SILVA, 2003).

Um dos indicativos para a seleção de plantas para este processo é o potencial para fitorremediação. Assim, qualquer fator que venha ocasionar alguma interferência negativamente no desempenho das plantas deve ser minimizado para favorecer sua ação descontaminante (BAKER, 1981). Várias espécies de macrófitas possuem altos índices de reprodução no Brasil, fato esse devido, principalmente, ao clima adequado para esse fim. A Eichhornia crassipes, mais conhecida como aguapé, é o exemplo mais clássico, o qual apresenta até $1000 \mathrm{~kg} /$ há dia de produtividade (COELHO, 1994). Uma planta promissora, que tem a capacidade de fixar em seus tecidos nutrientes em quantidades superiores às suas necessidades, bem como elementos químicos estranhos ao seu metabolismo (DENÍCULI et al., 2000).

Moraes e Rodrigues (2002) asseguram que a capacidade das macrófitas aquáticas reterem nutrientes tem atraído o interesse dos pesquisadores, e que a oferta de nutrientes, resulta na proliferação dessas plantas, com reservatórios propícios. Entre alguns reservatórios, podemos citar a bacia hidrográfica Apodi/Mossoró, um dos recursos hídricos do Rio Grande do Norte mais importante, que está sofrendo uma contaminação crescente em sua área territorial com o grande avanço econômico da cidade de Mossoró, que faz com que indústrias se instalem na cidade.

Segundo Bernardi et al. (2009) as características físico-químicas, biológicas e hidrológicas em qualquer ponto de um ambiente refletem muitas influências, incluindo o clima, geologia, geomorfologia e cobertura vegetal da região. Pode-se avaliar que sob equilíbrio dinâmico, esses fatores favorecem as normas e características ambientais naturais do sistema. Além dos ecossistemas terrestres adjacentes e do grau de alteração, a composição da água depende das atividades humanas exercidas em diversos segmentos do sistema (construção de represas, efluentes industriais e domésticos, drenagem de áreas alagáveis) que por sua vez, modificam as características físico-químicas e qualidade das mesmas. 
Assim, em meio a tanta poluição, nos últimos anos passou-se a dar mais importância a estudos que envolvessem o ambiente natural e a utilização de técnicas de remediação, para que diminuíssem os impactos negativos das atividades humanas. Além disso, deve-se preocupar com a espécie utilizada na fitorremediação, pois precisam atender as exigências fisiológicas das plantas, para que não ocorra o comprometimento do crescimento e da produção (LOPES, 2003).

Desta forma, este trabalho teve como objetivo estudar o potencial fitorremediador de macrófitas aquáticas da espécie Eichhornia crassipes presentes no rio Apodi/Mossoró em relação aos teores de alguns elementos utilizando a técnica de Fluorescência de Raios-X.

\section{METODOLOGIA}

Os métodos de análises utilizados seguiram a recomendação da metodologia descrita do Manual de análise química de solos, plantas e fertilizantes da EMBRAPA (1999) e Standard Methods of APHA (2006), os quais são descritos a seguir.

\subsection{Coleta das amostras}

Foi realizada uma coleta durante o mês de junho, em um ponto localizado no trecho do Rio Apodi/Mossoró que corta a cidade de Mossoró, taticamente escolhido devido às quantidades de plantas existentes naquela região. Foram coletadas água e macrófitas aquáticas da espécie Eichhornia crassipes.

As amostras de água foram coletadas sempre próximas às margens do rio em frascos de vidro âmbar, devidamente etiquetadas, colocadas em uma caixa de isopor e conduzidas para o laboratório de química geral da Universidade Federal Rural do Semi-Árido - UFERSA, Campus Caraúbas, para posterior análise. A água coletada para a análise de metais foi acidificada com $1 \mathrm{ml}$ de $\mathrm{HNO}_{3} \mathrm{P}$. A. / Litro de amostra, no momento da coleta.

As plantas aquáticas foram coletadas aletoriamente, independente da idade ou tamanho e foram armazenadas em sacos plásticos e conduzidas para o laboratório da UFERSA para a limpeza e o tratamento prévio.

\subsection{Tratamento das amostras}

Para as amostras de macrófitas aquáticas, fez-se uma separação entre as folhas (limbo + pecíolo) e a raízes, lavadas com água da torneira e enxaguadas com água deionizada. Após este processo elas foram colocadas em bandejas separadas e levadas para a estufa com circulação forçada de ar à $70^{\circ} \mathrm{C}$ para o processo de desidratação por um período de aproximadamente dois dias até atingirem peso constante. Depois de secas, foram trituradas separadamente, usando um liquidificador com lâminas de aço inoxidável e peneiradas para a homogeneização dos tamanhos das partículas. Em seguida, preparou-se os cadinhos, colocando aproximadamente 5,0 gramas de cada amostra (folhas e raízes) para serem calcinadas em uma mufla, onde ficou por 3 horas à temperatura de $550^{\circ} \mathrm{C}$. Após isso, as cinzas foram armazenadas em frascos plásticos tampados, devidamente limpos e secos e encaminhadas para a análise completa por Fluorescência de raios-X.

Para a análise de metais na água, as mesmas foram submetidas ao processo de digestão ácida de acordo com o método 3005 A da Agência de Proteção Ambiental dos Estados Unidos (USEPA). Assim, em um erlenmeyer, pipetou-se $100 \mathrm{~mL}$ da amostra de água, adicionou-se $2 \mathrm{~mL}$ de ácido nítrico $\left(\mathrm{HNO}_{3}\right)$ e $5 \mathrm{~mL}$ de ácido clorídrico ( $\mathrm{HCl}$ ), e a mistura foi aquecida a uma temperatura que variou entre $90^{\circ} \mathrm{C} \mathrm{e}$ $95^{\circ} \mathrm{C}$ em uma chapa aquecedora, promovendo uma redução substancial do seu volume entre 15 a $20 \mathrm{~mL}$. Depois deste procedimento, o digerido foi filtrado e diluído com água deionizada, a um volume conhecido para posterior análise. Preparado $100 \mathrm{~mL}$ da solução, a mesma foi levada à estufa, à $105^{\circ} \mathrm{C}$, para a secagem completa da água e obtenção dos sais sólidos. Estes, por sua vez, foram raspados, moídos por meio de um almofariz de porcelana para a homogeneização das amostras, armazenados, encaminhados para o laboratório de química da UERN e submetidos à análise.

Para todas as amostras foram utilizadas um sistema em duplicata, tanto para a água quanto para as plantas aquáticas. 


\subsection{Análise de diferenciação das médias}

A partir dos resultados obtidos, utilizou-se o programa ASSISTAT Versão 7.7 beta para realização do teste de Tukey a fim de analisar estatisticamente a diferenciação de médias entre os elementos quantificados nas folhas e raízes da Eichhornia crassipes.

\subsection{Fator de Translocação e Fator de Bioacumulação}

Os fatores de translocação e bioacumulação são usados para a identificação da capacidade acumuladora das plantas em relação a diversos elementos que podem ser absorvidos pelas mesmas. Os fatores de Translocação e Bioacumulação foram calculados através das equações 01 e 02 descritas abaixo.

$$
F T=\frac{C F}{C R}
$$

Onde: FT= Fator de translocação; $\mathrm{CF}=$ Concentração dos elementos nas folhas; $\mathrm{CR}=$ Concentração dos elementos nas raízes.

$$
F B=\frac{C T}{C A}
$$

Onde: $\mathrm{FB}=$ Fator de bioacumulação; $\mathrm{CT}=$ Concentração total dos elementos nas plantas (folhas+ raízes); $\mathrm{CA}=$ Concentração dos elementos na água.

\section{RESULTADOS E DISCUSSÕES}

A tabela 1 e os gráficos 1 e 2 mostram os dados obtidos pela técnica Flourescência de Raios-X, na amostra da água do rio Apodi/Mossoró. Foram identificados teores de bromo, cálcio, ferro, potássio, manganês, rubídio, enxofre, silício e estrôncio. Diversos fatores podem ter colaborado para esses resultados, como ações antropogênicas, geologia local, estações climáticas e variáveis ambientais da água.

De acordo com Araújo e Pinto Filho (2010), as indústrias são os principais responsáveis pela disposição de metais pesados como cádmio, ferro, cromo, chumbo e zinco no leito do rio.

Observa-se que na água do Rio o Cálcio apresentou um maior teor de concentração (66,927\%) em relação aos demais. $\mathrm{O}$ alto percentual de Ca pode está associado a questões geológicas, devido às características calcárias do solo da região, onde causa um aumento significativo nos valores encontrados na água. Resultados semelhante foi encontrado também na literatura por Martins et al. (2008a; 2008b) no leito do rio, na mesma localidade.

A segunda maior concentração na água foi do enxofre (13,107\%), onde constituem uma fonte significativa de poluição atmosférica biogênica e antrópica e, consequentemente, podem ser culpados por danos ambientais, incluindo participação na deposição ácida (CRUZ e CAMPOS, 2008). Abessa e Burone (2003) também encontraram teores de enxofre no Rio Grande de Ubatuba o que possivelmente causou toxidade significativa nas águas. 
Tabela 1 - Concentrações dos elementos pela FRX

\begin{tabular}{|c|c|c|c|c|c|}
\hline \multirow{2}{*}{ Analito } & \multicolumn{5}{|c|}{ CONCENTRAÇÕES } \\
\hline & Água do Rio & Folha & Raiz & FT & FB \\
\hline Br & 0,392 & $0,058 \mathrm{a}$ & $0,294 a$ & 0,196 & 0,897 \\
\hline Ca & 66,927 & $31,407 a$ & $23,924 b$ & 1,313 & 0,827 \\
\hline $\mathbf{F e}$ & 1,369 & $0,138 b$ & 7,691a & 0,018 & 5,719 \\
\hline $\mathbf{K}$ & 9,628 & $30,904 a$ & $11,991 b$ & 2,577 & 4,455 \\
\hline Mn & 0,219 & $0,499 b$ & $12,925 a$ & 0,039 & 61,297 \\
\hline $\mathbf{R b}$ & 0,043 & 0,023a & 0,019a & 1,216 & 0,953 \\
\hline S & 13,107 & 0,694b & 5,329a & 0,130 & 0,459 \\
\hline Si & 7,054 & $1,125 b$ & $16,244 a$ & 0,069 & 2,462 \\
\hline $\mathrm{Sr}$ & 1,080 & $0,132 \mathrm{a}$ & $0,040 \mathrm{~b}$ & 3,300 & 0,159 \\
\hline Cl & 0,000 & $29,980 a$ & $11,572 b$ & 2,591 & - \\
\hline $\mathbf{P}$ & 0,000 & $4,741 \mathrm{a}$ & $4,717 \mathrm{a}$ & 1,005 & - \\
\hline $\mathbf{T i}$ & 0,000 & 0,016b & $0,451 \mathrm{a}$ & 0,034 & - \\
\hline Zn & 0,000 & 0,010a & 0,038a & 0,267 & - \\
\hline Al & 0,000 & $0,000 \mathrm{~b}$ & 4,911a & 0,000 & - \\
\hline $\mathrm{Cu}$ & 0,000 & 0,033 & 0,000 & 0,033 & - \\
\hline $\mathbf{V}$ & 0,000 & $0,000 \mathrm{~b}$ & 0,069a & 0,000 & - \\
\hline $\mathbf{Y}$ & 0,000 & 0,000 & 0,001 & 0,000 & - \\
\hline $\mathrm{Zr}$ & 0,000 & 0,000a & 0,003a & 0,000 & - \\
\hline As & 0,000 & 0,000a & 0,003a & 0,000 & - \\
\hline $\mathrm{Cr}$ & 0,000 & 0,000a & 0,008a & 0,000 & - \\
\hline Eu & 0,000 & 0,000a & $0,212 \mathrm{a}$ & 0,000 & - \\
\hline $\mathbf{N i}$ & 0,000 & 0,000 & 0,002 & 0,000 & - \\
\hline Pd & 0,000 & 0,000a & $0,005 a$ & 0,000 & - \\
\hline Ba & 0,000 & 0,000 & 0,000 & 0,000 & - \\
\hline
\end{tabular}

As médias seguidas pela mesma letra minúscula na linha não diferem estatisticamente entre si. Foi aplicado o Teste de Tukey ao nível de 5\% de probabilidade.
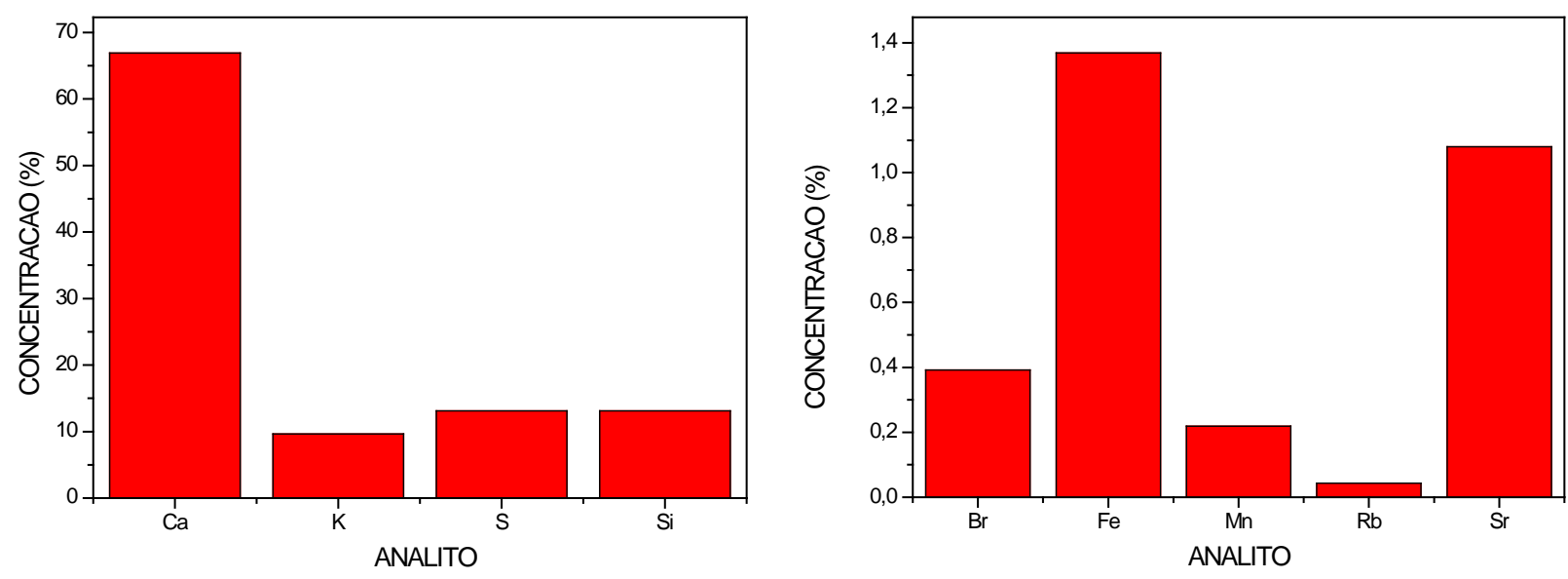

Gráficos 1 e 2 - Concentrações dos elementos na Água do Rio Apodi/Mossoró 
Com relação ao potássio (9,628\%), a terceira maior concentração, um valor significativo, é explicado devido ao lançamento de águas residuárias domésticas e industriais na região, e ainda ao efeito da região litorânea. Com o aumento das marés, o aumento das salinidades da água é constatado em localidades bem próximas aos pontos de coleta referenciados no presente trabalho, podendo assim, sofrerem algum efeito positivo na concentração destes elementos (MARTINS et al., 2008a; 2008b).

O silício por sua vez apresentou uma porcentagem na água de 7,054\%, provavelmente isso deve ao fato de que ele fundamenta estruturas e processos geológicos, biológicos, antropológicos e econômicos. De acordo com Lazzerini e Bonotto (2014), as águas superficiais e as de aquíferos rasos possuem concentrações e teor de silício influenciado pela temperatura atmosférica, presença de $\mathrm{CO}_{2}$, sílica livre nos solos, salinidade, matéria orgânica, tempo de contato e distância percorrida, a que se explica esse teor.

O Ferro, com a concentração de 1,369\%, está relacionado com a precária conservação dos solos no meio rural, e a ausência de matas remanescentes, intensificando os processos de erosão e assoreamento em solos formados a base de sesquióxidos de ferro, acrescendo consideravelmente a quantidade de solo em contato com a água, resultando no aumento da concentração de ferro, tanto solúvel como em suspensão com a água (HERNANDEZ et al., 2001 apud BARBOZA, 2010).

O Sr com sua concentração na água de (1,080 \%) é encontrado em tubos de televisores, como constituintes na indústria açucareira, e tudo isso quando jogado ao rio, causa poluição. Um resultado semelhante é o de Queiroz (2009) que também encontrou resquícios de estrôncio nas águas brancas (ricas de sedimentos em suspensão) do rio Solimões.

O Bromo apresentou um teor de (0,392\%), quando comparado com outros trabalhos sobre águas, pode-se citar o de Frizzo (2006), que encontrou também o elemento Bromo em diversas águas de abastecimento público. O Rubídio outro elemento encontrado, se explica devido à utilização em tubos de vácuo, como carbonato de rubídio empregados na indústria vidreira, com aplicação de medicamentos, apresentou o teor de $0,043 \%$, quase imperceptível.

Com relação ao Manganês o teor encontrado foi de 0,219\%, e pode ser entendido como tendo uma origem natural. No entanto, esse teor pode ser provocado pela poluição antropogênica em consequência da presença de lixões, valas negras e grande número de fossas na região. A composição disto é proveniente tanto dos lixões (no caso, o chorume) como do próprio esgoto in natura liberado pelas fossas e valas da região (FREITAS et al., 2001).

As macrófitas aquáticas tem a capacidade de estocar nutriente, devido sua capacidade de retêlos em sua biomassa. Thomaz (2002) destaca que essas plantas encontram nos ambientes eutrofizados as condições adequadas para o seu crescimento, por meio da capacidade de retenção de nutrientes. De acordo com os dados podemos destacar que todos os elementos apresentados na água do rio, também tiveram influência com relação à absorção nas plantas.

Quanto a questão fisiológica, analisada na tabela 1 e os gráficos 3 e 4, percebe-se que os elementos Br, Fe, Mn, S, Si, Ti, Zn, Al, V, Y, Zr, As, Cr, Eu, Ni, Pd, apresentaram maiores concentrações nas raízes do que nas folhas. Já os elementos $\mathrm{Ca}, \mathrm{K}, \mathrm{Rb}, \mathrm{Sr}, \mathrm{Cl}, \mathrm{P}, \mathrm{Cu}$, apresentaram comportamento inverso, ou seja, maiores nas folhas.

Analisando os resultados entre folha e raiz, foi utilizado um tratamento estatístico de diferenciação de médias, o teste de Tukey, ao nível de 5\% de probabilidade.

Para os elementos como Br, Rb, P, Zn, Zr, As, Cr, Eu, Pd, as letras iguais indicam que os valores médios entre a folha e a raiz não diferem entre si, ou seja, analisando estatisticamente os resultados são iguais.

Os gráficos 5 e 6 apresentam os valores para os fatores de translocação e os gráficos 7 e 8 para o de bioacumulação que foram possíveis de calcular. Quando esses parâmetros apresentam valores maiores que 1, há uma indicação da elevada taxa de absorção do elemento e sua preferência em se acumular na parte aérea. 

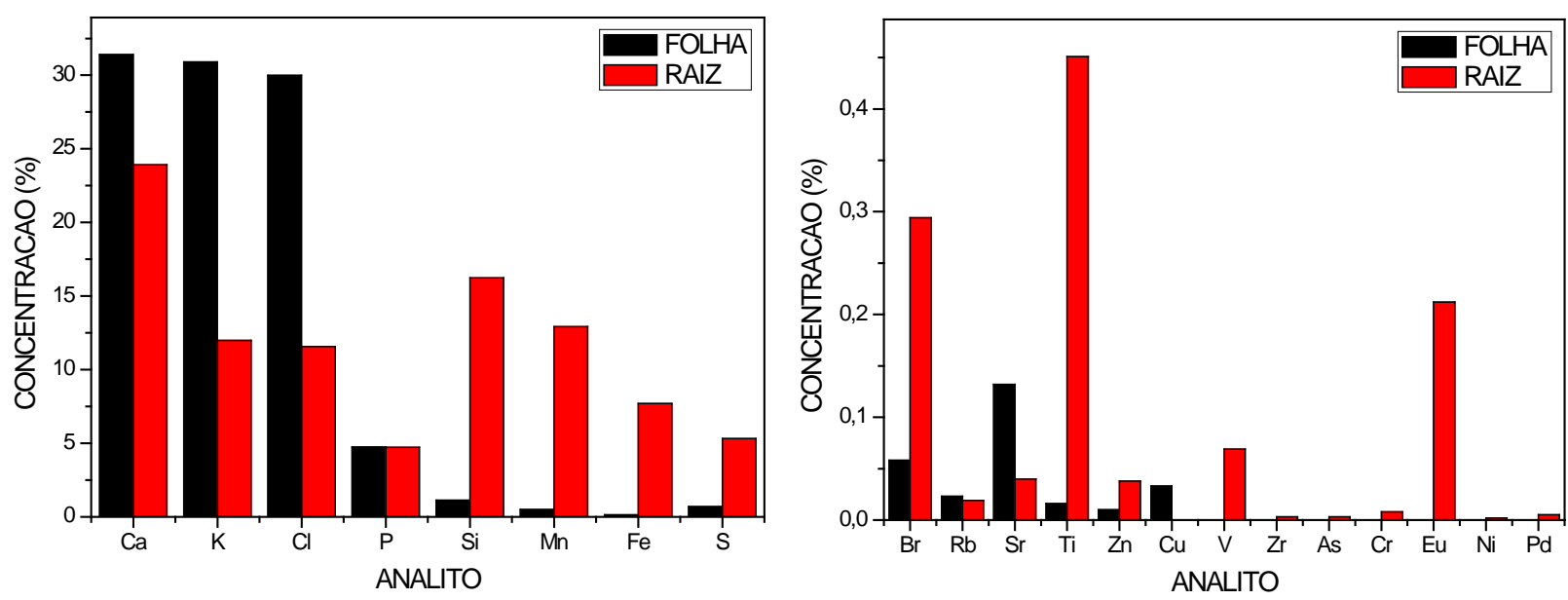

Gráficos 3 e 4 - Concentrações dos elementos nas folhas e raízes
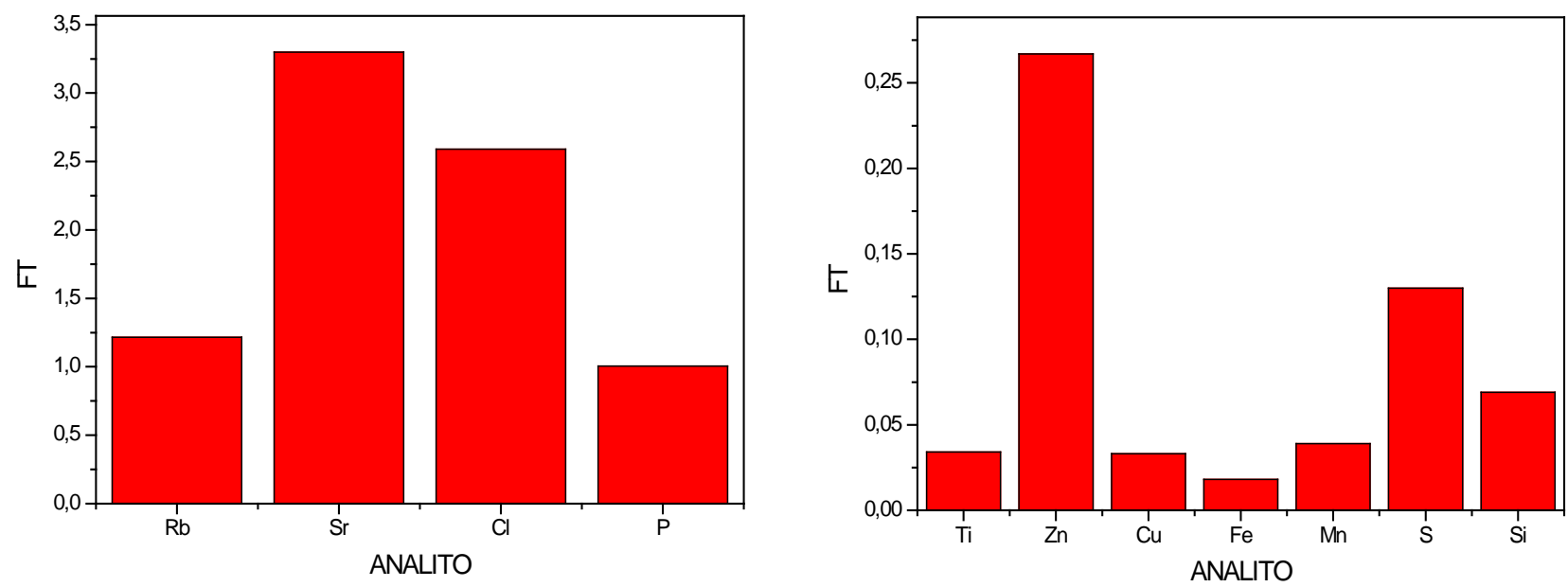

1

Gráficos 5 e 6 - Fator de translocação das plantas (FT)
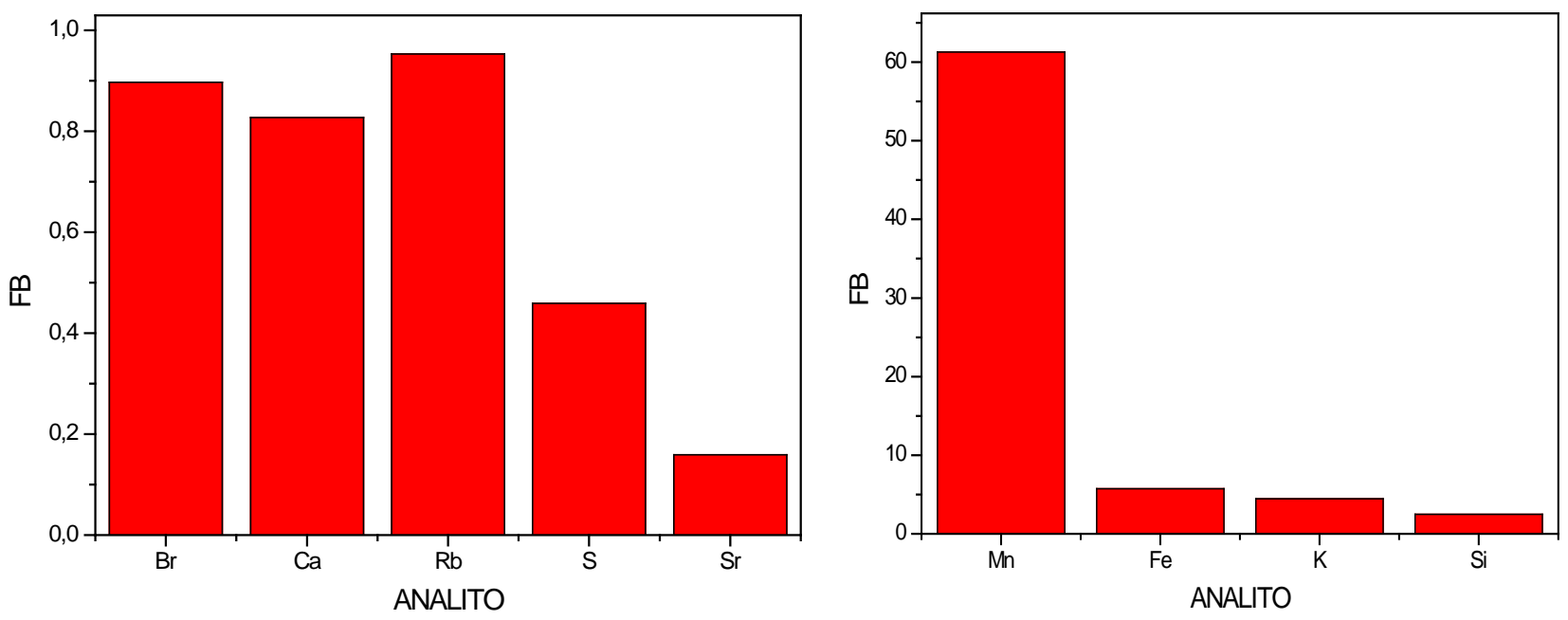

1

Gráficos 7 e 8 - Fator de Bioacumulação das plantas (FB) 
Os elementos como Br, Fe, Mn, S, Si, Ti, Zn, Al, Cu, V, Y, Zr, As, Cr, Eu, Ni, Pd apresentaram os valores do fator de translocação abaixo de 1 . Para o enxofre, um macronutriente, esperava-se que apresentasse um comportamento diferente, ou seja, apresentasse em maior quantidade nas folhas, no entanto, pode ser explicado devido ao processo metabólico das plantas.

Com relação ao fator de biocumulação, percebe-se que os elementos como Si, Fe, K, Mn, apresentaram valores maiores que um. Assim, pode-se afirmar que a planta apresenta facilidade em bioacumular esses elementos em seu tecido vegetal.

Em meio essa discussão, pode-se destacar elementos que não foram possíveis de se calcular o fator de bioacumulação, que estão expressos na tabela 1. Esse parâmetro é determinado a partir da relação entre os valores da concentração no tecido vegetal e da água. Assim, os que apresentam concentração igual à zero na água, impossibilitaram a realização do cálculo, por não ser possível uma divisão por zero.

Todos esses resultados se tornam de extrema importância quando se pretende analisar o potencial fitorremediador da Eichhornia crassipes em um ambiente natural como o rio Apodi/Mossoró. Essa espécie apresenta um grande potencial para ser usada como agente fitorremediador nesses ambientes naturais, tendo em vista a quantidade acumulada de cada elemento em seu tecido vegetal.

Vardanyan e Ingole (2006) analisaram o potencial fitorremediador de várias espécies de macrófitas aquáticas. Determinaram a habilidade de absorção de metais pesados (14) por plantas aquáticas (45) pertencentes a oito famílias, em duas localidades, mas especificamente 36 no lago Sevan, Armênia e nove no lago Carambolim, Old Goa, Índia. Assim, de acordo com eles, a maior parte dos metais se acumulou nas raízes, o que é de se esperar devido a não essencialidade dos mesmos ao crescimento das plantas. Também foi observado que a ocorrência das espécies metálicas nas plantas foi maior na localidade do lago Sevan, o que mostrou que a variabilidade na capacidade de remoção e recuperação de ambientes poluídos com diferentes características.

Palma-Silva et al. (2012) mostrou que a espécie apresenta um potencial fitorremediador em ambientes eutrofizados no sul do Brasil. Também foi observado que apresentaram um maior desenvolvimento conforme o tempo de permanência no lago para dois nutrientes $(\mathrm{N}, \mathrm{P})$ analisados. Kumar (2012) mostrou a eficiência da Eichhornia quanto à taxa de remoção do $\mathrm{Cu}$ e Ni, dentre cinco espécies analisadas, o que leva a ter um potencial fitorremediador para estes elementos. Já o trabalho de Fox et al. (2008) mostrou que o aguapé foi responsável por 60-85\% do N removido a partir da solução, tornando-o um agente fitorremediador para esse elemento.

\section{CONCLUSÃO}

Conclui-se que atualmente, a contaminação dos ambientes aquáticos por metais poluentes é um grave problema ambiental, devido sua persistência e elevado poder de toxicidade. Com isso, estudos sobre a fitorremediação estão sendo desenvolvidos visando uma série de benefícios para o meio ambiente e as futuras gerações. A Eichhornia crassipes apresentou altas concentrações de nutrientes em sua biomassa quando coletada em ambiente natural. Em geral, os macronutrientes se apresentaram em maiores concentrações nas folhas, enquanto os micronutrientes apresentaram-se em quantidades maiores nas raízes, um comportamento já esperado, na qual se encontra na literatura explicando as funções da essencialidade dos mesmos ao desenvolvimento das plantas. Assim, devido aos fatores de translocação e bioacumulação a espécie estudada apresentou um grande potencial para ser utilizada como agente fitorremediador em ambientes eutrofizados de todos os elementos quantificados, em função das concentrações acumuladas no seu tecido. Observa-se ainda que carecem estudos específicos sobre plantas que possuem a habilidade de fitorremediar. 


\section{DETERMINATION OF POTENTIAL PHYTOREMEDIATION OF NATURAL ENVIRONMENTS IN EICHHORNIA CRASSIPES}

Albstract: Among the various activities developed by man, some of them have the ability to release contaminants that are dangerous to human health and other life forms such as animals and plants, causing environmental degradation. Therefore, increases the interest in remedial techniques in order to recover all or part of environments impacted in particular by human action. Among them, the Phytoremediation is highlighted due to its efficiency in decontaminating eutrophic environments and because of its low cost compared to others. Thus, this study aims to determine the phytoremediation potential of aquatic macrophytes of the specie Eichhornia crassipes present in the river Apodi / Mossoró in relation to the contents of some elements using fluorescence technique of $\mathrm{X}$-ray. The gathering of water and used plants was made on the section of the river Apodi / Mossoró which crosses the city of Mossoró. Based on the results obtained were identified in the water of the river $\mathrm{Br}, \mathrm{Ca}, \mathrm{Fe}, \mathrm{K}, \mathrm{Mn}, \mathrm{Rb}$, $\mathrm{S}$, Si and Sr, and about the plant was noted that the elements, Br,Fe, Mn, S, Si, Ti, Zn, Al, V, Y, Zr, As, $\mathrm{Cr}, \mathrm{Eu}, \mathrm{Ni}, \mathrm{Pd}$, has presented in higher concentrations in the roots than in the leaves. In the other hand, the elements $\mathrm{Ca}, \mathrm{K}, \mathrm{Rb}, \mathrm{Sr}, \mathrm{Cl}, \mathrm{P}, \mathrm{Cu}$, presented an opposite behavior, the concetration was higher in the leaves. Hence, this species has great potential to be used in phytoremediation strategies of natural environments, depending on the amounts accumulated in their tissue.

Keywords: Phytoremediation; Eichhornia crassipes, Rio Apodi/Mossoró; Contaminated environments; anthropogenic action.

\section{REFERÊNCI AS BI BLIOGRÁFICAS}

ABESSA, D. M. S.; BURONE, L. Toxidade de sedimentos dos rios situados na enseada de Ubatuba (SP, Brasil). Mundo Saúde, v. 27, n. 4, p. 564-570, 2003.

ARAÚJ O, J. B. S.; PINTO FILHO, J. L. de O. Identificação de fontes poluidoras de metais pesados nos solos da Bacia Hidrográfica do Rio Apodi/Mossoró/RN, na área urbana de Mossoró-RN. Revista Verde de Agroecologia e Desenvolvimento Sustentável, Mossoró, v.5, n. 2, p. 80-94, 2010.

ARAÚJ O, V. S.; SANTOS, J. P.; ARAÚJ O, A. L. C.; Monitoramento das águas do rio Mossoró/ RN, no período de abril/ 2005 a julho/ 2006. Holos, 2007.

BAKER, A.J. .M. Accumulators and excluders strategies in the response of plants to heavy metals. J. Plant Nutrition, 3:643-654, 1981.

BARBOZA, G. C.; HERNANDEZ, F. B. T.; FRANCO, R. A. M.; MORAES J. F. L.; SILVA, P. T. P. Concentração de ferro na água para irrigação na microbacia do coqueiro, Estado de São Paulo. III WI NOTEC - Workshop Internacional de I novações Tecnológicas na I rrigação, 2010.

BERNARDI, J. V. E.; LACERDA, L. D.; DÓREA, J. G.; LANDI M, P. M. B.; GOMES, J. P. O.; ALMEIDA, R.; MANZATTO, A. G.; BASTOS, W. R. Aplicação da análise das componentes principais na ordenação dos parâmetros físico-químicos no alto Rio Madeira e afluentes, Amazônia Ocidental. Geochimica Brasiliensis. v. 23, n. 1, p. 79-90, 2009.

BIANCHINI JR., I.; PACOBAHYBA, L. D.; CUNHA-SANTINO, M. B. Aerobic and anaerobic decomposition of Montrichardia arborescens (L.) Schott. Acta Limnol. Bras. v. 14, n. 3, p. 27 34, 2002. 
CAMARGO, A. F. M.; PEZZATO, M. M.; HENRY-SI LVA, G. G. 2003. Fatores limitantes à produção primária de macrófitas aquáticas. In: THOMAZ, S. M. e BINI, L. M. Ecologia e Manejo de Macrófitas Aquáticas. Editora da Universidade Estadual de maringá. Cáp. 3, p. 59-83.

COELHO, T. Aguapé: bom, bonito e barato. Ecologia e Desenvolvimento, n. 38, p. 2-4, 1994.

CRUZ, L. P. S.; CAMPOS, V. P. Métodos de amostragem e análise para compostos reduzidos de enxofre atmosférico. Química Nova, v. 31, n. 5, p. 1180-1189, 2008.

DENÍCULI, W. et al. Uso de aguapés na redução de sólidos totais de águas residuárias da suinocultura. Engenharia na Agricultura, Viçosa, v. 8, n. 1, p. 38-51, 2000.

FOX, L. J.; STRUIK, P. C.; APPLETON, B. L.; RULE, J. H. Nitrogen Phytoremediation by water Hyacint (Eichhornia crassipes (Mart.) Solms). Water Air Soil Pollut, v. 194, p. 199-207, 2008.

FREITAS, M. B.; BRILHANTE, O. M.; ALMEIDA, L. M. Importância da análise de água para a saúde pública em duas regiões do Estado do Rio de Janeiro: enfoque para coliformes fecais, nitrato e alumínio. Saúde Pública, Rio de Janeiro, v. 17, n. 3, p. 651-660, 2001.

FRIZZO, S.J. Elementos químicos (Metais pesados) em águas de abastecimento público no estado do Ceará. Secretaria de Geologia, Mineração e Transformação Mineral. CPRM - Serviço Geológico do Brasil, 2006.

GHOSHROY, S.; FREEDMAN, K.; LARTEY, R.; CITOVSKY, V. Inhibition of plant viral systemic infection by non-toxic concentrations of cadmium. The Plant J ournal, v. 13, n. 5, p. 591 - 602, 1997.

KUMAR, N.; BAUDDH, K.; DWIVEDI, N.; BARMAN, S. C.; SINGH, D. P. Accumulation of metals in selected macrophytes grown in mixture of drain water and tannery effluent and their phytoremediation potential. J ournal of Environmental Biology, v. 33, p. 923-927, 2012.

LAZZERI NI , F. T.; BONOTTO, D. M. O silício em águas subterrâneas do Brasil. Revista do Centro de Ciências Naturais e Exatas - UFSM. Santa Maria, v. 36, n. 2, p. 159-168, 2014.

LOPES, B. A. Aspectos importantes da fisiologia vegetal para o manejo. Disciplina ZOO 750. $55 f$. Programa de Pós-Graduação em Zootecnia, Universidade Federal de Viçosa , Viçosa, 2003.

MARTINS, D. F. F. et al. Qualidade físico-química das águas da bacia do Rio Apodi/Mossoró: I Variabilidade espacial. Química no Brasil, v. 2, n. 1, p. 61 - 74, 2008 .

MARTINS, D. F. F.; SOUZA, L. D.; CASTRO, S. S. L. Qualidade físico-química das águas da bacia do Rio Apodi/Mossoró: II - Variabilidade temporal. Química no Brasil, v. 2, n. 2, p.9 - 23, 2008b.

MORAES, A. J.; RODRIGUES, J. B. Remoção de fósforo com uso de macrófitas em lagoa facultativa de frigorífico. Medianeira, 2002. 52f. Monografia (Graduação em Tecnologia Ambiental) - Centro Federal de Educação Tecnológica do Paraná.

PIRES, F. R.; SOUZA, C. M.; SILVA, A. A.; PROCÓPIO, S. O.; FERREIRA, L. R. Fitorremediação de solos contaminados com herbicidas. Planta Daninha, v.21, n.2, p.335-341, 2003.

PALMA-SILVA, C.; ALBERTONI, E. F.; TRINDADE, C. R. T.; FURLANETTO, L. M.; ACOSTA, M. C. Uso de Eichhornia crassipes (Mart.) Solms para fitorremediação de ambientes eutrofizados subtropicais no sul do Brasil. Perspectiva, Erechim, v. 36, n. 133, p. 73-81, 2012.

QUEI ROZ, M. M. A. Composição química e isótopos de estrôncio das águas ao longo do rio Solimões na região entre Manacapuru e Alvarães - Amazonas - Brasil. 2006. 78 f. Dissertação (Mestrado em Geociências) - Programa de Pós-Graduação em Geociências, Universidade Federal do Amazonas, Manaus. 
SILVA, S. S. L. Caracterização ecológica e estrutural de macrófitas em reservatórios no estado de Pernanbuco. Recife, 2011. 107p. Tese (Doutorado). Universidade Federal de Pernanbuco. THOMAZ, S.M. Fatores ecológicos associados à colonização e ao desenvolvimento de macrófitas aquáticas e desafios de manejo. Planta Daninha, v.20, p.21-33, 2002.

VARDANYAN, L. G.; INGOLE, B. S. Studies on heavy metal accumulation in aquatic macrophytes from Sevan (Armenia) and Carambolim (India) lake systems. Environment International, v.32, p.208 218, 2006. Disponível em: <http://drs.nio.org/drs/bitstream/handle/2264/226/Environ_Int_32_208.pdf;jsessionid=12FA885411B 48E466F1F1958AE4EC12E? sequence=1>. Acesso em: 16 set 2015. 